\title{
La noción de espacio público y la configuración de la ciudad: fundamentos para los relatos de pérdida, civilidad y disputa
}

\author{
Héctor Berroeta Torres \\ Universidad de Valparaíso, Valparaíso Chile. Email: hector.berroeta@uv.cl \\ Tomeu Vidal Moranta \\ Universitat de Barcelona, Barcelona España. Email: tvidal@ub.edu
}

\begin{abstract}
Resumen: Como cualquier constructo social, la noción de Espacio Público es fruto de un proceso sociohistórico, su definición es diversa y según su uso se presta para la identificación de diferentes situaciones. En este texto se revisan las diversas nociones del espacio público en su dimensión comunicativa y se describen los elementos de correspondencia en la ciudad construida. Este ejercicio se plantea como marco comprensivo para situar una propuesta de organización de los relatos actuales con que el discurso de lo urbano comprende y actúa sobre la ciudad. Se argumenta la identificación de un discurso del espacio público como perdido, el de un espacio público como espacio de construcción de civilidad y el de un espacio público como espacio de control y disputa. Se concluye la importancia de develar estos discursos y la pertinencia de utilizar el relato del control y la disputa para analizar las recientes luchas sociales.
\end{abstract}

Palabras clave: Espacio público, esfera pública, ciudad, espacio urbano

\section{The notion of public space and the shaping of the city: A framework for the stories of loss, civility and dispute}

\begin{abstract}
As any social construct, the notion of public space is the result of a socio-historical process; its definition is diverse, and according to its use it is appropriate for the identification of different situations. In this paper we review the different notions of public space in its communicative dimension and describe the elements of correspondence in the built city. This exercise arises as a comprehensive framework to situate a proposal of organization of current discourses through which urban discourses understand and act upon the city. It discusses the identification of a discourse of public space as a lost space, of public space as construction of civility and of public space as a space of control and dispute. It concludes stating the importance of uncovering these discourses and the adequacy of using the narrative of dispute and control to analyze recent social struggles.
\end{abstract}

Key words: Public space, public realm, city, urban space

\section{A noção de espaço público e na configuração da cidade: a base para histórias de perda de civilidade, e disputa}

Resumo: Assim como qualquer construção social, a noção de espaço público é o resultado de um processo sóciohistórico, sua definição é diversa, e de acordo com sua utilização estiver prevista a identificação de situações diferentes. Neste artigo analisamos as várias noções de espaço público na sua dimensão comunicativa e descrevemos os elementos de correspondência na cidade construída. Este exercício é colocado como um quadro global para fazer uma proposta de organização dos relatos atuais com que o discurso do urbano compreende e age sobre a cidade. Discutemos a identificação de um discurso do espaço público como perdido, do espaço público como espaço de construção da civilidade e do espaço público como um espaço de controle e disputa. Concluímos a importância de descobrir esses discursos ea adequação do uso da relato da disputa para controlar e analisar recentes lutas sociais.

Palavras-chave: Espaço público, esfera pública, Cidade, área urbana

\[ * * \]
"Las historias sobre el origen del Espacio público no tratan del pasado: nos hablan de las preocupaciones y
ansiedades que habitan en nuestros ordenes sociales presentes"

(Deutsche, 2001: 312). 


\section{Introducción}

La visión del espacio público como un espacio de construcción de ciudadanía y encuentro social, está anclada a la reflexión política acerca de lo público-privado; accesibilidad, transparencia y libertad. El análisis del espacio público es una cuestión que involucra un aspecto discursivo y filosófico, pero que también se expresa en el lenguaje de los planificadores y arquitectos, que de una u otra forma refiere a aspectos de la promoción o el control de la sociabilidad y el encuentro social que se produce en la construcción de la ciudad (Borja \& Muxi, 2001; Salcedo, 2002).

En este trabajo presentamos una revisión de lo que planteamos como relatos sobre el espacio público. En los dos primeros aparatados abordamos los aspectos centrales que distinguen las diversas aproximaciones sobre el componente comunicativo del término o lo que más habitualmente se denomina esfera pública y su expresión en la conformación morfológica de la ciudad. Distinguiremos dos visiones acerca del espacio público que según Weintraub (1995), se encuentran en la base de los distintos desarrollos conceptuales: la versión Clásica, de estirpe greco-romana-republicana, y la visión Moderna, ligada a las prácticas sociales que se dan en la ciudad multifuncional y compacta.

Estas dos visiones son el sustrato sobre el que se articulan las lecturas específicas respecto a la esencia, configuración y proyección del espacio público en la ciudad actual. Distinguiremos estas diversas lecturas, organizando sus discursos en tres grandes relatos: el relato de un espacio público perdido, el de un espacio público como espacio de construcción de civilidad y el de un espacio público como espacio de control y disputa.

La lectura transversal de estos contenidos, nos deja asentada la comprensión de que el espacio público está constituido por esta doble dimensión, política y urbana. No es posible entender una sin la otra. La visión clásica o moderna del discurso político, no se comprende sin su correlato físico en la historia de la ciudad, mientras que los diversos relatos, no son legibles sin su vinculación al discurso político que los sustenta. En consecuencia, el modo en que organizamos y practicamos el espacio público urbano, es también el modo en que (des)construimos un discurso societal.

\section{Las nociones de espacio público y su correlato en la ciudad}

\section{La versión clásica}

Existe consenso (Ferry, J., Wolton, D. et al., 1995; Habermas, 1994; Arendt, 1958; Rabotnikof, 1997) en situar en la Grecia clásica la primera distinción entre lo público y lo privado en la configuración de las ciudades-estado. Es a partir de los griegos que la democracia, y por tanto, la propia política se vinculan a un espacio de convivencia específico — el Ágora - donde se consiguen las decisiones mediante la discusión pública, las que luego se establecen como condiciones necesarias para la convivencia civil. A partir de la consolidación progresiva del modelo democrático griego, se van construyendo en torno a este espacio diversos edificios dedicados al bien público y al ejercicio democrático. Transformando al Ágora en el centro político de la ciudad (Goitia, 1970).

La concepción griega acerca de lo privado, lo público y lo político, concibe lo público como lo propiamente político, es decir, la expresión del hombre libre que alcanza su trascendencia histórica a través de su expresión en un lugar común, situación que es posible al estar libre de las obligaciones de la vida cotidiana; en tanto lo privado, corresponde a los bienes — cosas, animales y personas - de un dueño y que por tanto, se encuentran "privados" de derechos políticos.

El espacio público desde este planteamiento es el lugar de la expresión pública del interés común, donde el ser humano busca los lazos compartidos y la diferenciación. En cambio el espacio privado es aquel en que se asegura la reproducción de la vida. "Lo público remite a la acción y al discurso; lo privado, a la reproducción y al trabajo. Lo público es lo aparente y manifiesto; lo privado, lo oscuro que debe ser ocultado, 
sustraído a la mirada de los demás. Lo público es el espacio de la libertad, de la capacidad de inicio de algo nuevo; lo privado, el ámbito de la necesidad, de la reproducción” (Arendt, 1958: p.71).

En el tipo de racionalidad subyacente en la noción de Espacio Público que plantea Arendt, la política se basa en la pluralidad de los hombres y en su posibilidad de estar juntos, la libertad es la condición de conformación del espacio público, lo que a su vez configura el mundo como diverso. La visión de fondo que aquí se sustenta, es la idea de que los hombres son sujetos plurales y únicos, capaces de expresar un pensamiento diverso (Sahui, 2002). Se reivindica la singularidad de los hechos concretos, donde la responsabilidad es identificable. Se valora la opinión más que la verdad, sobre la base de que "el mundo siempre es observado desde un número infinito de posiciones diferentes, a las que corresponden los más diversos puntos de vista en un flujo de argumentos totalmente inagotables" (Arendt, 1958: 59), desde ahí se apela a la noción de sentido común como criterio de validez en contra de la racionalidad universal. Se refiere al pre entendimiento compartido por una comunidad, que se expresa en un lenguaje común como parte de una cultura y modo de vida compartido. Es decir, lo adecuado está dado por los acuerdos de una comunidad y sus horizontes de valores, siempre que estos no atenten contra la pluralidad que define el espacio público. Por tanto, la racionalidad se conceptualiza como una razón práctica que distingue lo correcto de lo incorrecto desde un marco comunitario y no racional objetivo; noción que se asocia fuertemente a la idea de pertenencia, identificación y cultura compartida, propias de la constitución de un sentido de comunidad.

En suma, desde esta posición se entiende la política "dentro del espectro de racionalidad intersubjetiva que en una comunidad dada nos constriñe a pensar desde el lugar del otro, a ejercer nuestra imaginación representativa" de ahí que la idea de espacio público se significa como "un espacio de relaciones entre individuos quienes, a través del discurso y sus acciones, contribuyen a modelar el mundo común como un horizonte de entendimiento y encuentro ciudadano" (Sahui, 2002: 261-262).

Desde esta perspectiva la coincidencia entre la dimensión política y urbana del concepto es clara. En el Ágora no existe soporte de mediación alguno, el intercambio discursivo entre los ciudadanos se da cara a cara en un espacio de encuentro y de toma de decisiones sobre los asuntos de interés colectivo, el Espacio público en la polis griega se expresa colectivo, abierto y manifiesto. Lo jurídico-político se ejercita públicamente en el Ágora. La res-pública es lo que pertenece al pueblo que no refiere al patrimonio de uso público, sino a la gestión, es decir, es el pueblo quien administra lo público, no es el acceso en sí, es una comunidad de derecho basada en la utilidad común, que se distingue de lo privado del patrimonio y del comercio (Rabotnikof,1997).

Sin embargo, es necesario clarificar que no se trata de un espacio marcadamente inclusivo, sino más bien, altamente elitista, exclusivo del ciudadano miembro de la polis. Las minorías no participan de él, es un espacio marcadamente homogéneo, monofuncional, cuya capacidad para la formación de sociabilidad y convivencia es restringida. Como señala Habermas "En la ciudad-estado griega plenamente formada, la esfera de la polis, común al ciudadano libre, está estrictamente separada de la esfera oikos, en la que cada uno ha de apropiarse aisladamente de lo suyo (...) El orden político descansa, como es sabido, en una economía esclavista de forma patrimonial. Los ciudadanos están descargados del trabajo productivo (...) La posición en la Polis se basa, pues, en la posición del oikodéspota." (Habermas, 1994: p.43).

En la alta y baja edad media se dan cuenta de formas organizativas y urbanas distintas, aquellas cuya dependencia es directa del poder señorial o propio de la autorganización, donde la ciudadanía se instala como derecho individual al servicio de la organización. A diferencia del Ágora, la plaza pública medieval no posee un marco arquitectónico que separe el espacio público de los barrios residenciales, las calles se ligan directamente con ellas y las propias construcciones marcan sus límites. Alrededor de la plaza se disponen los edificios comunitarios principalmente los edificios municipales y religiosos.

La ciudad se caracteriza por ser una unidad compacta e interrelacionada, donde cada elemento pertenece a la trama general; edificios, plazas y calles se disponen en un juego de llenos y vacios que articulan las funciones urbanas (Mumford, 1979). Se trata de un urbanismo "orgánico" (Delfante, 2006; Benevolo, 1993) que responde más a las necesidades y funciones que a la planificación teórica, consiste fundamentalmente en un proceso de adaptación, de un orden natural donde no existe una supeditación formal en la edificación. En general, en la Edad Media se desarrollan grandes proyectos arquitectónicos asociados al Imperio y la Iglesia-Estado, se dan en paralelo la construcción de las grandes catedrales góticas y la 
construcción de una metafísica de la creación en el terreno de la filosofía y la teología. El gobierno urbano medieval no es el producto de una aplicación doctrinal, sino de razonamientos espontáneos, exigidos por nuevas condiciones de vida. Condiciones que como refleja Busquets (2004) llevarán a que la articulación de poderes se complejice en la baja edad media. Ya no se tratará exclusivamente de una visión sagrada de intermediación real entre Dios y los hombres, se expresarán más los papeles y atributos distintivos de las personas y sus oficios, generándose nuevas estructuras de gobierno que desde esta visión darán paso al renacimiento.

El componente más característico de la morfología de la ciudad son sus murallas de protección, estas no sólo inciden profundamente en su desarrollo urbano, sino que además determinan la conformación de un orden político y administrativo que se consolida con la creación del Ayuntamiento. Dos aspectos que marcan el desarrollo urbanístico y ciudadano de la ciudad son el derecho a vender y comprar libremente el suelo urbano, lo que propicia un tipo de edificación autónoma y favorece el desarrollo mercantil y el derecho a la ciudadanía para los habitantes de la ciudad, fenómeno que rompe con el derecho señorial y propicia la generación de un lazo comunitario.

En relación al tipo de espacio público político o de esfera pública, Habermas (1994) expresa la indiferenciación medieval entre las categorías de lo público y lo privado, tal cual las entendemos actualmente o como se expresaban en el periodo clásico, señala "me parece más clarificador entender que las facultades privadas y públicas de dominio se mezclan en una unidad inextricable, de modo que ambas emanan de un poder unitario, están adheridas a la tierra y pueden ser tratadas como legítimos derechos privados" (Idem, 1994: P 45), de esta forma se entiende que el sentido de la publicidad representativa hace referencia a que el soberano y sus estamentos están para representar a su propio dominio, en una posición que no es para el pueblo, sino ante el pueblo. En consecuencia el señor feudal esta por sobre de la distinción público-privado, posee un estatus que lo instituye como la corporización de un poder superior, es así que el "derecho público y privado forman una masa indistinta y homogénea" (Radbruch, 1951), como ocurre por ejemplo en las relaciones de vasallaje que se encuentren normadas por el derecho público.

En el espacio público de la edad media se destaca el sentido de lo abierto y accesible en oposición a lo particular. Se expresa en la distinción entre espacios de uso común y espacios de uso reservado o particular. Existe una publicidad representativa separada de las cuestiones comunes que opera como manifestación encarnada del poder en el estatus señorial. Sin embargo, a pesar de que la figura del soberano era absoluta, existían límites jurídicos que eran insuperables. La razón pública estaba ligada a una razón comunitaria asociada al gobierno de la ciudad, donde las prioridades de las instituciones públicas y el gobierno se encontraban por encima de los intereses privados de los ciudadanos (Rabotnikof, 1997).

Como señala Rabotnicof la construcción del estado y el desarrollo del mercado irán perfilando el sentido moderno de la escisión entre esfera pública y privada. (Rabotnicok, 1997: p. 138).

\section{La versión moderna}

El espacio público moderno es una creación de la ilustración, como señala Koselleck, el principio rector será la inversión de la afirmación de Hobbes, "la verdad, y no la autoridad, hace la ley" (Koselleck en Ferry, 1995: p.15).

La ciudad durante el Renacimiento experimenta un crecimiento importante. El poder absoluto no sólo crea nuevas infraestructuras defensivas — cuarteles y arsenales - sino también construye obras educativas y solidarias - escuelas, hospitales, hospicios, bolsas, teatros, museos, etc. Aparecen los primeros jardines privados que progresivamente se convertirán en espacios públicos.

El desarrollo tiene lugar principalmente en los barrios céntricos donde predominan palacios, monumentos y hermosas plazas que ganan significativamente con la creciente valoración del artista y la proyección geométrica, sin embargo, producto de una exacerbada migración campo-ciudad y la consecuente especulación del suelo, se genera una edificación cada vez más densa, que afecta fundamentalmente a los barrios pobres. Las condiciones de vida de este sector empeorarán progresivamente, hasta llegar al contexto 
infrahumano alcanzado por la ciudad industrial de inicios del s. XIX que Federico Engels (1845) describe con certeza.

Lo público pasa a ser lo colectivo, que se contrapone al ámbito privado entendido como lo económico y lo religioso. La conformación de un entramado público dirigido al bien colectivo (autoridades, edificios, servicio, etc.) va a delimitar por oposición lo que es de interés privado.

Es en el siglo XVIII cuando se decantan las ideas más innovadoras para la configuración de la ciudad moderna que se harán efectivas en el siglo siguiente (Busquets, 2004). Una forma de pensar la ciudad racional de forma variada y ordenada superará definitivamente la caótica ciudad medieval. Se recurre a una metáfora médica para transformarla apelando a cuestiones sanitarias, de orden social y de seguridad, con medidas tales como sacar los cementerios fuera de la ciudad; la creación de nuevas plazas para conseguir ventilación y asoleo; la reorganización de los mercados; la instalación de fuentes y la segregación de las calles para el tránsito de carruajes y peatones; son propuestas por Pierre Patte, para París, en el 1765.

Por otra parte, como describe Fernández Christlieb (2004), durante el siglo XVIII estalla la sociedad de los cafés, espacio necesario por el crecimiento y despersonalización de la ciudad como efecto del mercantilismo y la migración. En estos lugares se produce la comunicación libre, centrada en los problemas del buen gobierno de la ciudad, los nuevos espacios suscitan el "interés de las autoridades por utilizar la prensa de acuerdo con los objetivos de la administración (....) para dar a conocer órdenes y disposiciones. Se convirtieron los destinatarios propiamente por vez primera en público" (Habermas, 1994), claro está que este público no es el del hombre común de los bajos barrios, sino el de un grupo social ilustrado, de una nueva capa burguesa - funcionarios gubernamentales, médicos, juristas, curas oficiales y profesores-, como apunta Habermas, es un público de lectores.

La Declaración de derechos del hombres y del ciudadano de 1789 viene a consagrar la libertad de pensamiento y difusión de ideas, la tolerancia y la igualdad ante la ley y libertades de asociación y movimiento, principios que consolidan una nueva relación entre lo público y lo privado. Se instaura así una publicidad crítica, surgida en el seno de lo privado, que somete a juicio permanente el quehacer estatal. Se conforma lo que se conocerá posteriormente como sociedad civil.

Es a partir de este marco que se articula la propuesta Habermasiana de esfera pública burguesa cuyo principio crítico es la publicidad, es decir, el ideal kantiano de que "las opiniones personales de individuos privados podían desarrollarse en el medio de una opinión pública a través de un proceso de debate racionalcrítico abierto a todos y libre de dominación" (Thompson, 1996: p.4). Esta propuesta de Habermas en el valor crítico de la publicidad opera como principio normativo para la constitución de una democracia deliberativa. Esta idea de un espacio deliberativo, refuerza la noción de un espacio público en el que los sujetos comparten y dialogan cara a cara en un contexto de igualdad. La prensa y los medios de comunicación aportan los contenidos y estimulan la conversación Burguesa. Como señala Thompson (1996 p.10) "la esfera pública fue constituida por encima de todo por medio del habla, en la contraposición de argumentos, opiniones y puntos de vista diferentes del intercambio dialógico de palabras habladas en un espacio compartido".

La acción deliberativa del espacio público se orienta desde la razón, que no es otra cosa que la capacidad discursiva de los sujetos ilustrados e informados con criterio. Como plantea Boladeras (2001) la subjetividad burguesa se funda en el interés por descubrir los secretos de la naturaleza humana asociados a la idea de humanidad ilustrada, en la que se asocia razón humana y naturaleza humana.

Rabotnicof (1997) define a la esfera pública planteada por Habermas según tres características: a) Burguesa, en tanto son los propietarios independientes, cuyo estatuto coincide con la calificación en términos de educación, los que participan en la generación de una voluntad colectiva a través de un proceso de comunicación racional libre de dominación; b) Liberal, en tanto los derechos que aseguran la autonomía de esta esfera, en conjunción con los que aseguran el ámbito de autonomía individual, consolidan al mismo tiempo la esfera pública y privada de la sociedad civil y se erigen en barreras para la intromisión del poder público y c) Democrática o potencialmente democrática, en el sentido de que el poder burocráticamente organizado es controlado y equilibrado por una esfera público-política que, emergiendo de la sociedad civil, penetra en el estado en la forma del parlamento (Rabotnicof, 1997 p. 145). Habermas (1994) plantea un 
espacio público que se caracterizaría por ser un espacio de expresión de una publicidad crítica al servicio de una sociedad civil reguladora del aparato estatal y de sus formas de organización.

Sin embargo, esta concepción del espacio público no escapa a la misma crítica planteada a la visión clásica, también se cuestiona que se trate de un espacio exclusivo para quienes tenían los medios, el conocimiento y la validación cultural para participar, dejando excluidos de él a obreros, campesinos y mujeres entre otros grupos sociales. Otra crítica importante es la posición central y determinante que ocupa el consenso racional en la construcción del discurso democrático.

Esta apuesta por una racionalidad normativa en el discurso moderno del espacio público tiene efectos directos sobre la organización, diseño y los usos del espacio público urbano, se expresa por ejemplo en las normativas de convivencia que comienzan a instaurarse en diversas ciudades europeas apelando a un consenso racional de usos adecuados e inadecuados, mismo argumento con el que se justifica el creciente control policial del espacio urbano.

En síntesis, en esta noción de espacio público, siguiendo a Rabotnicof (1997), desde una posición normativa se vuelven a reunir los tres sentidos de lo público: lo común, la accesibilidad y lo público propiamente tal. En el primer sentido, la racionalidad asociada al ejercicio de lo público permitirá la integración social a partir de la determinación de los bienes y garantías públicas, las que se establecen a partir de normas generales comunes a todos los ciudadanos. En relación a la apertura, esta estaría asegurada en tanto se trataría de una esfera independiente de la del mercado y asegurada por la capacidad representativa de un determinado círculo social homogéneo, existiría un alto grado de control por parte de los ciudadanos hacia quienes tienen el poder, lo que aseguraría la transparencia.

La forma de organización de la ciudad cambia radicalmente durante el siglo XIX, el uso del espacio como lugar de representación del poder soberano da paso a lo que Foucault (2005) llama "organizar un espacio analítico", eliminar la circulación difusa propiciando el control selectivo y disciplinar del habitante urbano. Las ciudades industriales de fines del s. XVIII y principios del XIX se ven marcadas por las transformaciones tecnológicas asociadas al desarrollo industrial y la nueva relación entre el Estado y los privados determinada por el liberalismo de Smith y la economía de David Ricardo. Como plantea Delfante "La posición, siempre desfavorable, de la fuerza de trabajo con respecto al imperio del capital y a una base estructural inmutable, tiene influencia sobre la forma de la ciudad, porque la propiedad del suelo y de los bienes de consumo se convierten en capital y en mercancía" (Delfante, 2006: p. 273) lo que genera la profunda crisis social y el escenario de caos descrito por Engels (1845).

Como efecto de las crecientes movilizaciones sociales emergen respuestas de reordenamiento de la ciudad. Eugene Georges Haussmann en París entrega el modelo funcional para reformar la ciudad Europea. Se llevan a cabo grandes instalaciones y servicios: alcantarillado, red hidráulica, alumbrado a gas, transportes púbicos, escuelas, hospitales, mercados y parques. La red viaria es modificada construyéndose nuevas calles anchas y rectas, desapareciendo los barrios pobres y el entramado de callejuelas tan utilizado en los disturbios revolucionarios, para favorecer el movimiento policial. Las intervenciones de Hussmann no sólo modificarán el entorno físico de la ciudad sino también afectarán directamente su forma de gestión. Se marca una separación taxativa entre el espacio público y el privado, cuya consecuencia es el usufructo privado de las transformaciones realizadas por el estado y las dificultades históricas de manutención de estos espacios, como señala Benevolo "la renta inmobiliaria, que extrae riqueza de la esfera pública y la acumula en la privada, acentúa el contraste entre ambos espacios" (Benevolo, 1993, p.185).

Para Delfante (2006) el XIX es un siglo que marca un quiebre con la concepción tradicional de la ciudad, el marco ya no es el valor arquitectónico del espacio, sino la organización urbana como conjunto, determinada por las relaciones sociales y económicas.

En este contexto de transformaciones tiene lugar el declive de la esfera pública burguesa tal como la presenta Habermas, dos son los factores de base: primero, la separación entre Estado y Sociedad Civil que se descompuso en cuanto el Estado se hizo más intervencionista y responsable de la administración de los bienes ciudadanos, en la medida que los grupos de interés se impusieron en el proceso político; segundo, la transformación y la desaparición de las instituciones que albergaron la esfera pública burguesa, la mutación 
de las prácticas culturales que provocan el declive de los salones y casas de café y la transformación de la prensa periódica en una empresa comercial al servicio del lucro individual y la dominación de masas. Esto último a decir de Habermas (1994) es el elemento central de la transformación de la publicidad crítica en una publicidad manipuladora dirigida a la masa consumidora. "la publicidad burguesa, a medida que va configurándose de acuerdo con las public relations, recobra características feudales: 'los portadores de la oferta' desarrollan toda una pompa 'representativa' ante los atentos clientes. La publicidad imita ahora aquella aura de prestigio personal y de autoridad sobrenatural tan característica en otra época de la publicidad representativa" (Habermas, 1994: p.222). Por tanto, se está en presencia de un sistema de aclamación plebiscitaría de una masa despolitizada, donde la mayoría de la población queda excluida de la participación política y sometida a la voluntad de los grupos socialmente dominantes.

En la segunda mitad del XIX y la primera del XX se producen los grandes y radicales enfrentamientos de clase, se pasa a la sociedad de masas y a la cultura tecnológica. Se crean formas nuevas de acumulación de capital que suscitan cambios importantes en la sociabilidad; se consagra el voto universal; y se diluye la separación entre lo público y lo privado (Boladeras, 2001). Por tanto, la noción de opinión pública cambia de sentido "ya no se trata del concepto normativo de una opinión formada con la razón, sino más bien se refiere a una masa segmentada de opiniones particulares en la que se expresan intereses divididos y hasta conflictivos" (Ferry, 1995: p. 17) se pasa de una "sociedad de masas" a una "sociedad de medios" que a decir de diversos autores (Ferry 1995; Wolton, 1995) configuraran una nueva noción de Espacio Público.

La ciudad se concibe desde la idea de fragmento, una concepción topológica del espacio que surge de las transformaciones tecnológicas en el campo de la comunicación y el transporte, desarrollo que se puede analizar en diversos ciclos; primero en la primera mitad del siglo XIX ligado a la mejora de la red viaria y a los comienzos del transporte ferroviario; segundo, en la segunda mitad del siglo XIX, ligado al pleno desarrollo de las redes ferroviarias y del telégrafo; el tercero, en la primera mitad del siglo XX, ligado al desarrollo de autopistas y a la radio; y el cuarto, al desarrollo de la electrónica y la telemática en la segunda mitad del s. XX (Secchi, 2005).

\section{La versión contemporánea}

La ciudad del siglo XXI resulta más difícil distinguir aún, dado que las actividades humanas, inicialmente localizadas dentro de las ciudades, ahora se extienden ampliamente en el territorio, consumiendo áreas rurales y naturales. El transporte y otras redes de infraestructura construidas para conectar estas actividades dispersas, despacio pero inexorablemente unen las ciudades pequeñas y grandes, para crear un continuo urbano (Consejo Europeo de Urbanistas, 2003).

En este contexto de desarrollo acelerado de las tecnologías y expansión del capitalismo neoliberal emergen nuevos negocios asociados a la circulación mediática. Estos medios, especialmente la televisión, se transforman en actores sociales que se redefinen progresivamente como actores políticos en alianza con los poderes político y financiero (Cisneros, 2003). Esta nueva estructura mediática entre privados, estado y sociedad civil será denominada por los expertos como un Nuevo Espacio Público articulado a partir de las dinámicas de mediación de la actividad política producto de la difusión de los medios masivos de información y representación política.

Este Nuevo Espacio Público corresponde al "marco mediático gracias al cual el dispositivo institucional y tecnológico propio de las sociedades post-industriales es capaz de presentar a un público los múltiples aspectos de la vida social" (Ferry, 1995). Siendo el público todos aquellos que pueden percibir y comprender los mensajes difundidos, no se restringe a una delimitación de ciudad o estado, más bien se trata de un intercambio entre sociedades.

Desde esta noción, el espacio público corresponde al marco mediático en el que se presentan al público los distintos contenidos de la vida social. Entendiendo por mediático, lo que mediatiza la comunicación de las sociedades consigo misma y entre sí (Ferry, 1995). En consecuencia, lo que cualifica al espacio público son

los soportes de comunicación que posibilitan la difusión masiva de algún contenido, por tanto, una opinión colectiva sólo accede al espacio público cuando es capaz de llegar a un público amplio a través de algún 
medio de comunicación que asegura su participación. Es decir, la noción de espacio público ya no se refiere al orden de lo jurídico o sociopolítico, sino más bien al ámbito de la divulgación.

Desde esta posición el espacio urbano de libre acceso y de tenencia pública, ya no serían espacios públicos propiamente tal, más bien serían medios para acceder al verdadero espacio público que son los medios de comunicación.

Para Ferry (1995) en la sociedad actual el espacio público se ha ampliado horizontal y verticalmente. En la primera dirección el incremento cuantitativo del público receptor, ya no se trataría sólo de un cuerpo electoral específico circunscrito a un estado nación, son considerados público todos aquellos sujetos capaces de recibir y comprender un mensaje. Respecto a la ampliación vertical, se daría tanto por la capacidad que tiene el espacio público de fortalecer la identidad colectiva a través de la apropiación de la historia en la actualización del pasado de una sociedad, como por la inclusión de nuevos contenidos que se instalan en el espacio público, eventos que antes eran considerados propios de la esfera íntima actualmente se presentan como contenidos que alcanzan el interés general.

Esta perspectiva nos plantea que el eje central del espacio público político se ha desplazado desde la publicidad crítica al espacio de la opinión pública. Esto quiere decir que no toda la comunicación política se encuentra integrada en el espacio público, es posible distinguir; una comunicación política de las masas, sustentada en las interacciones directas, cara a cara, que si bien no logran alcanzar el espacio público si pueden incidir en la construcción de la opinión pública; y por otro lado las minorías privilegiadas cuentan con información de contenido político que maneja intencionadamente en secreto y que a pesar de no ser parte del dominio de la opinión pública, tienen por lo general la capacidad de incidir en las decisiones políticas. A decir de Ferry (1995) estamos ante una subversión del reino de la crítica por un reino de la opinión, es decir, el espacio público político ya no está regulado por los principios universales de la ética y el derecho, ha dejado de estar orientado por un ideal argumentativo o deliberativo como diría Habermas, se encuentra dominado por las reacciones a las opiniones difusas de la sociedad civil. En consecuencia la acción política responde más al control de la opinión pública que se visibiliza en la comunicación política — los sondeos- que a una acción racional y representativa.

Para Rabotnicof (1997) se estaría en presencia de un espacio público que dista sustancialmente del espacio público ilustrado y que se sitúa en un complejo esquema de sociedad civil. En relación al sentido de lo abierto, de lo accesible se trata de un espacio que tiende a ser de un acceso masivo en su condición de soporte mediático, sin embargo, en su dimensión de espacio político es restringido a los actores políticos y a los medios, el ciudadano común queda exento de una participación activa, su acción es pasiva como receptor de la información. Con respecto a la transparencia en oposición a lo secreto, la privatización y concentración de los medios articula una dinámica selectiva de manipulación política y empresarial que condiciona radicalmente los contenidos que emergen o no a la luz pública.

\section{Los relatos del espacio público en la ciudad actual: Perdida, civilidad y disputa}

Desde un punto de vista urbano, en la discusión actual se mantiene la referencia a los contenidos de diálogos libres y entre iguales, propios de la visión Habermasiana y Arendtiana, desde la cual se busca dar forma a las características deseables del espacio urbano como un lugar de encuentro social y de usos mixtos.

En el relato genérico de los administradores se mezclan dimensiones sociales, políticas y urbanísticas bajo premisas ideales de igualdad y democracia. Indiferenciadamente, se transita por propuestas societarias o comunitarias, reclamando la construcción de espacios representativos y a la vez convivenciales, que por su sola edificación resultan garantes de la sociabilidad democrática. La categoría espacio público "es utilizada en un doble sentido: por una parte, en un sentido muy tradicional y operativo, como el espacio abierto de la ciudad (las calles y las plazas), sin más contenido teórico que el supuesto de que es en el espacio abierto donde la sociedad se reúne y reconoce; y por la otra, adscribiendo automáticamente para ese espacio abierto todas las cualidades sociales y políticas que las teorías del espacio público ponen en circulación" (Gorelik, 2008: P.44). 
Si se consideran las funciones sociales y las capacidades reales que tiene todo proyecto urbano, las consecuencias para la construcción de ciudad de esta indiferenciación son particularmente paradójicas y amenazantes. Los gestores urbanos se amparan en este relato superficial de civilidad y democracia para justificar sus intervenciones privatizadoras y coercitivas, obviando el sustrato ideológico-normativo del espacio público. Como plantean Dixon, Levine y McAuley (2006), la libertad y la diversidad en el espacio público están limitadas, tanto por variables de seguridad, como por imperativos culturales de orden y decoro moral.

Sin embargo, los límites y posibilidades del espacio público en la ciudad contemporánea, han sido analizados por visiones teóricas más específicas. En ellas se examina la capacidad de la ciudad para sostener los valores (utópicos) que sustentan las nociones del Espacio Público que describimos en los apartados anteriores. Estas reflexiones tienen en común, plantear su propia valoración de los contenidos democráticos que la ciudad permite, describir las condiciones específicas en que esto tiene lugar y analizar el modo en que se construye y gestiona la ciudad actual. Ordenamos estos relatos en los siguientes tres tipos de visiones: el Espacio Público Perdido; el Espacio Público como Construcción de Civilidad y el Espacio Público como Espacio de Control y Disputa.

\section{El Espacio Público Perdido}

Corresponde a los planteamientos que describen la pérdida del espacio público democrático en la sociedad contemporánea y que denuncian la emergencia de fenómenos de privatización, en lo que se ha llamado la disolución de la ciudad. Se cuestiona fundamentalmente la capacidad cohesionadora del sistema de espacios públicos, y la creciente privatización urbana, cuyas manifestaciones ejemplares, se encuentran en la substitución de las calles y las plazas por un conjunto de artefactos urbanos de dominio privado y la transformación del paisaje urbano por fenómenos de homogenización de la ciudad, hipervigilancia y control espacial.

El supuesto de base de esta perspectiva es que el espacio público en algún momento fue un lugar de expresión democrático, donde predominaban la diversidad de usos y el encuentro social (Salcedo, 2002; Gorelik, 2008), hipótesis desde la cual se contrasta la actual situación de la ciudad contemporánea. Sennett (1974), uno de los exponentes más celebres de esta posición, lo resume muy bien cuando señala: "la ciudad ha servido como foco para la vida social activa, para el conflicto y el juego de intereses, para la experiencia de la posibilidad humana, durante la mayor parte de la historia del hombre civilizado. Pero precisamente esa posibilidad civilizada se encuentra hoy adormecida" (Sennett, 1974: p.416)

En su libro "El declive del hombre público", este sociólogo norteamericano explica que el proceso de individuación, que caracteriza a la sociedad contemporánea, ha instalado la creencia actual de que los significados sociales son generados por los sentimientos de los seres humanos individuales, fenómeno que ha originado la destrucción de lo público en desmedro de lo privado.

Ideales como libertad, igualdad, tolerancia y respeto a la diferencia, que fueron señas de identidad de la perspectiva democrática en la que surgió la ciudad, han sido reemplazados gradualmente por la fragmentación y la separación estricta de los espacios, avalada por una seguridad cada vez más sofisticada y estructurada sobre el aumento de la desigualdad. "Estrategias que introducen transformaciones en el paisaje urbano que afectan patrones de circulación, hábitos y rutinas relacionadas con el uso de las calles, del transporte público, de los parques y de los espacios públicos en general" (Caldeira, 2000:297).

Estos cambios en las formas en que se configura real y simbólicamente la ciudad y la vida pública, componen un conjunto de fenómenos socio-urbanos que desplazan el eje de la convivencia de lo público a lo privado; emergen espacios pseudopúblicos que vienen a reemplazar los entornos de sociabilidad tradicionales, la calle es reemplazada por corredores o túneles peatonales (Boddy, 1992), el mercado, por los centros comerciales (Crawford, 1992) y los barrios, por comunidades cerradas (Atkinson \& Flint, 2004); nuevas formas de control y seguridad modifican las dinámicas de sociabilidad posibles en la ciudad (Davis, 2003) y las estrategias de mercado, asociadas a estéticas globales, homogenizan los entornos urbanos (Sorkin,1992).

\section{Espacio público como Espacio de construcción de civilidad}


Esta posición sostiene que el Espacio público es el espacio principal del urbanismo, de la cultura urbana y de la ciudadanía, de cuya calidad, multiplicación y accesibilidad depende en buena medida el progreso de la ciudad. Esta perspectiva, que sin negar los fenómenos y consecuencias que la visión de la perdida describe sobre la ciudad, reivindica la necesidad de proyectar un mejor y más pertinente espacio público. La revisión de la literatura nos sugiere que es posible identificar dos trayectorias distintas al interior de este mismo enfoque, la tradición que llamaremos Norteamericana y la tradición que denominaremos Europea.

La tradición Norteamericana se funda en dos antecedentes específicos. Primero, un fuerte cuestionamiento al enfoque de la pérdida, en el que se cuestiona la creencia que presenta esta visión acerca de la existencia de un pasado mítico donde el espacio público fue completamente abierto, democrático e inclusivo, capaz de acoger a una diversidad siempre activa de usuarios (Brill, 1989). Segundo, un reconocimiento a la particularidad de la idiosincrasia y las condiciones de vida en Estados Unidos que marcan un desarrollo urbano distinto al europeo. En Estados Unidos se celebra la individualidad como rasgo distintivo del carácter nacional. La vida pública norteamericana no está asociada a las concentraciones urbanas, sino más bien a la vida de barrio, a las asociaciones privadas y a los medios de comunicación. La población es dispersa, segmentada y estratificada, lo que reduce la diversidad y la densidad en un mismo lugar, factores necesarios para que la vida pública se desarrolle en la calle, en las plazas o parques como ocurre en Europa.

Partiendo de esta base, la tradición norteamericana se orienta a la necesidad de adaptar el espacio público a las nuevas formas y funciones que demanda la vida pública actual en Norteamérica, destacando que estos cambios han producido un fuerte resurgimiento del espacio público, materializado en una mayor diversidad de entornos y soportes comunicativos (Brill, 1989; Carr, Francis, Rivlin y Stone, 1992). Estas nuevas funciones y demandas, asociadas fundamentalmente a cambios producidos en el balance entre la vida pública y privada, como consecuencia de una serie de transformaciones culturales, tecnológicas, políticas y económicas, fundan nuevos valores y estilos de vida que, a su vez, demandan nuevas formas de diseño y de gestión de los lugares (Ibid, 1992).

Desde esta posición se plantea que los principales motivos que han de orientar la generación o regeneración de espacios públicos son promover una mejorar en la calidad de vida de sus usuarios. Se debe proveer de bienestar público a través de la generación de zonas para el esparcimiento, el relajo y la recreación; mejorar visualmente las ciudades mediante el embellecimiento del diseño urbano; incrementar y preservar paisajes naturales que pugnen con la degradación ambiental; y favorecer el desarrollo económico asociado a la venta de productos, servicios orientados a los usuarios y el alza inmobiliaria.

Estos objetivos, más la necesidad de responder a demandas, cada vez más estratificadas y segmentadas de reunión en la vida pública, han materializado respuestas urbanísticas que desde esta tradición son considerados como nuevas tipologías de espacios públicos: centros comerciales, recintos feriales o parques temáticos (Carr, et al., 1992), así como un fuerte interés en la construcción de parques.

La Tradición Europea a diferencia de la Norteamericana, no sólo comparte el diagnóstico, sino también los supuestos, que plantea el discurso de la pérdida, sin embargo, se niega a participar de sus designios pesimistas. Borja (2003) lo describe del siguiente modo, "no nos encontramos ante la crisis de la ciudad, sino ante el desafío de hacer ciudad; ejercer el derecho a la ciudad por parte de los ciudadanos es lo que hace a la ciudad viva en el presente, capaz de reconstruir pasados integradores y proponer proyectos de futuro movilizadores" (Borja, 2003: p. 32). Para esta tradición, más allá de ser un recurso que provee bienestar, el espacio público es la condición básica para la existencia de la ciudadanía (Hassenpflug, 2002). El derecho a un espacio público de calidad es un derecho humano fundamental en nuestras sociedades.

Los antecedentes de este planteamiento se encuentran en el cuestionamiento a la Carta de Atenas y la subsecuente revalorización de la ciudad tradicional y de sus componentes colectivos: calles, plazas, manzanas cerradas, etc., (frente a la negación o el papel abstracto del espacio público y a la proliferación de bloques en los esquemas del urbanismo moderno) (Monclus, 2003). Estos cuestionamientos se proyectan en lecturas urbanas que revelan un renovado interés por la ciudad existente, como la "arquitectura de la ciudad" (Aldo Rossi, 1992), y la "reconstrucción de la ciudad europea". La ciudad europea se plantea ante todo como la 
centralidad de lo político, de los asuntos comunes y del espacio público, la identidad de la "ciudad europea" es el espacio que la sociedad civil produce y que al mismo tiempo requiere (Hassenpflug, 2002: p. 16).

Esta tradición se orienta a la revalorización de la ciudad histórica (sobre todo, la del siglo XIX y principios del XX), la reivindicación de los espacios públicos tradicionales (calles, plazas, parques) y a la integración de urbanismo y arquitectura (Monclus, 2003). A juicio de Hassenpflug (2002), la reconstrucción de la "ciudad europea" intenta corregir los fenómenos urbanos que se produjeron durante el siglo XX, el reemplazo de calles por vías para automóviles, de plazas y parques por lugares de estacionamiento, de frontis arquitectónicamente ricos por fachadas homogéneas prefabricadas y de espacios públicos por otros funcionales que habría conducido a procesos de suburbanización.

Esta reacción a la estrategia urbana modernista consolidó progresivamente el proyecto urbano como una alternativa arquitectónica al planeamiento generalista, los problemas urbanos son abordados mediante proyectos específicos, especialmente de recuperación de espacio público y equipamientos (López de Lucio, 2000). Se trata de un renovado interés por el papel y la formalización del espacio público, por el que se plantea la necesidad de recuperar calles, plazas y espacios "vacíos", dotar de centralidad y monumentalizar la periferia urbana. Los objetivos de estas actuaciones sobre el espacio público son mejorar la calidad urbana, pero también implementar una visión pragmática, donde el espacio público se concibe como ocasión de proyectos económicamente viables y con un proceso de gestión relativamente sencillo (Monclus, 2003).

Si bien los valores y los fundamentos para mejorar el diseño y la administración del espacio público varían entre las tradiciones, existen coincidencias importantes. Ambas visiones (Nortemericana y europea) atribuyen al espacio público una capacidad para estimular el comercio y para mejorar las condiciones de vida de los habitantes de clase media integrada en la ciudad; plantean la necesidad de incorporar las demandas y necesidades de los propios usuarios, con estrategias participativas que incorporan a los ciudadanos en la construcción de la ciudad.

\section{El Espacio público como espacio de control y disputa}

Se sustenta en una visión crítica de la concepción romántica de un espacio público igualitario y accesible, posición desde la cual se analiza la disputa entre el control de lo urbano y la subversión de las prácticas de apropiación. Esta perspectiva plantea que el espacio público nunca ha sido un lugar armónico y completamente accesible, se señala que siempre ha sido un lugar donde se han dado dinámicas inestables y procesos de exclusión.

Las dinámicas inestables y los procesos de exclusión se fundan en una lógica de control y disputa entre la estructura normativa de la sociedad hegemónica y las prácticas de acción de sujetos y colectivos con diferentes tipos de lazos con esa sociedad. Certeau (2006) describe bien la esencia de esta relación: "Una sociedad estaría compuesta de ciertas prácticas desorbitadas, organizadoras de sus instituciones normativas, y de otras prácticas, innumerables, que siguen siendo "menores", siempre presentes aunque no organizadoras de discurso, y aptas para conservar las primicias o los restos de hipótesis (institucionales, científicas) diferentes para esta sociedad o para otras" (Certeau, 2006: p.56).

La materialización de esta disputa en la ciudad, Delgado la sitúa entre la polis y la urbs, es decir "entre el orden político, relativo a la administración y la proyección centralizadas sobre la ciudad, y la urbanidad propiamente dicha - tránsitos y coaliciones temporales de los transeúntes-, resultado en gran medida del trabajo de una sociedad sobre sí misma" (Delgado, 2001: p.154). Por tanto el espacio público es visibilizado como en un permanente conflicto inestable.

Desde esta visión el espacio público sólo se constituye como tal cuando es apropiado por los usuarios, un espacio sólo es público mediante un trabajo de cualificación que remite a los momentos de acción y a las estructuras prácticas de la experiencia (Joseph, 1999). Es decir, las características físicas, sólo se constituirían en espacio público en el momento en que son apropiadas.

Michel de Certeau (Certeau, Giard, \& Mayol, 2006) explica estos procesos de apropiación utilizando como metáfora la lectura, la práctica en el espacio público es como la lectura del texto geométrico de la 
planificación urbana y la arquitectura funcionalista desde el consumidor cultural, es decir, el transeúnte pasa a ser el ejecutor de un acto creativo de rememoración y significación del espacio basado en trayectos y mapas, que establece una diferencia entre lugar y espacio, donde el primero vendría a ser la disposición geométrica de objetos en relación y el segundo, "un cruzamiento de movilidades", de operaciones que se actualizan en una contingencia circunstancial, y que instituyen un lugar practicado. Es el poder de los ciudadanos, en cualquier situación social y estructural, para transformar críticamente los usos y significados del espacio propuestos por los productores (Salcedo, 2002).

Este repertorio sobre el valor de la apropiación, se funda en la reivindicación de un derecho a la ciudad (Lefevbre, 1973) que le corresponde a todo habitante en cuanto sujeto que interactúa socialmente dentro del marco urbano y que reafirma la exigencia de una presencia activa. Este derecho del ciudadano sería efecto de la segregación de todo aquello que no tiene participación en los privilegios políticos, y a partir de lo cual se hace legítimo reivindicar el derecho a apoderarse, encontrar y reunir; lugares y objetos que respondan a determinadas "necesidades" no tenidas en cuenta y a determinadas funciones menospreciadas. Este derecho a la ciudad encuentra su condición de expresión natural en el espacio público, es en él donde se busca revertir una situación de necesidad o privación, opción política antagónica o un modo no reglado de recrear vínculos de sociabilidad, en un juego de confrontación entre públicos y contra-públicos que reproducen o desafían la concepción dominante de las relaciones sociales (Mitchell, 1995).

Como bien plantea Di Masso (2009), desde esta posición, el núcleo ontológico del espacio público es la dialéctica dominación-contestación, poder y resistencia, orden-transgresión, entre públicos y contrapúblicos en situación de desigualdad. Este autor, hace una exhaustiva revisión de las características y distinciones que adopta esta dialéctica en el espacio público y sus diferentes acepciones, en el marco de los discursos que él denomina "conflictivista".

Un primer aspecto que distingue son los diferentes papeles que desempeña el espacio público en esta dialéctica de confrontación. Citando a Burte (2003) señala que el espacio público puede ser objeto, escenario o precipitador de los conflictos o incluso las tres al mismo tiempo. Es decir, puede operar como objeto de conflicto por uso y ocupación, control y disputa en actividades consideradas (in)aceptables e (in)adecuadas, según la legitimidad de ciertos públicos a ocuparlos o tomar decisiones sobre él. Como escenario el espacio público es una plataforma para manifestar el disenso político, así como para el despliegue de violencia urbana sobre personas, inmuebles o mobiliario. Por último como precipitador, el espacio público puede transformarse en el depósito simbólico de la memoria colectiva que condensa significados y valores que expresan luchas pasadas ocurridas en el espacio público y que forman parte de la identidad y del pasado local.

Una segunda distinción es la identificación de dos tipologías de conflictos, blandos y duros, según sea la posición que ocupan los actores involucrados en la sociedad de referencia donde se produce el conflicto. Denominará conflictos blandos a aquellos que se derivan de la diversidad social, generalmente asociados a conflictos por concepciones normativas dispares, pero que se producen entre usuarios en igualdad de condiciones y estatus en el derecho a la ciudad. Se trata de usos incompatibles por contexto material o moral. Mientras que los conflictos duros, serán aquellos que se vinculan a la desigualdad social, donde hay una asimetría en el derecho a la ciudad entre los usuarios. Estos cuestionan directamente la calidad democrática del espacio público, los límites de la ciudadanía y los procesos políticos de exclusión social que operan sobre el territorio.

A partir de esta concepción Di Masso (2009) va más allá y plantea que se puede hablar de una relación asimétrica entre públicos fuertes y públicos débiles, según sea el estatus de su condición real o simbólica de ciudadano. En consecuencia, muchos de los juicios de inadecuación de determinados comportamientos en el espacio público, y las consecuentes prácticas formales e informales de censura y represión, funcionan como subterfugios para la reproducción de prácticas de discriminación social (racista, xenófoba o clasista).

Los grupos dominantes están siendo capaces, hoy en día, de excluir al resto de los actores sociales del uso de ciertos espacios a través de la creación de enclaves en los que el discurso del espacio público como lugar de encuentro social y construcción de ciudadanía se mantiene, pero se restringe sólo a ciertos segmentos de la sociedad. El espacio público es un lugar de expresión y ejercicio del poder, pero que es experimentado 
como tal sólo por los oprimidos; para el resto, tal como en la modernidad, es el espacio de construcción ciudadana y diálogo social (Salcedo, 2002).

Por tanto, desde esta posición se considera necesario concebir al público como una noción plural y contestada, defendiendo que los derechos ciudadanos a usar el espacio público deben basarse en reafirmar identidades, revertir desigualdades y preservar diferencias.

En suma y según Di Masso (2009): "El conflicto en el espacio público es necesario tanto para visibilizar la injusticia de la exclusión como para socavar su gramática dominante. Es en este sentido que el espacio público es el escenario material para el cambio social y, siendo así, es un termómetro de la calidad democrática de una sociedad que debe ser capaz de aceptar y afrontar el conflicto urbano desde sus raíces estructurales".

\section{Conclusiones}

En la concepción clásica, el ámbito público es el espacio de la comunidad política, se fundamenta en la ciudadanía y se expresa en una activa participación colectiva en la toma de decisiones. Su encarnación física y social es la "polis" (autónoma, deliberativa y democrática), materializada en el ágora como espacio de discusión y confrontación. La visión moderna, ligada a la ciudad industrial europea, el espacio público reduce su intensidad participativa y coincide con la trama de calles y plazas de la ciudad, es una red de espacios en la que tiene lugar la convivencia colectiva cotidiana, marcada por la coexistencia inmediata de individuos y actividades, de proximidad física y distancia social, en un juego permanente de tensiones en las que emerge la representación como forma de participación política. En su versión contemporánea existe una dramática separación entre los actores políticos, los grupos de poder y los ciudadanos comunes. Hay un gran desequilibrio entre los distintitos grupos de interés, la esfera relacional se encuentra cooptada por los medios de comunicación y el espacio de la ciudad se segrega, controla y homogeneíza.

La distinción de esta trayectoria conceptual y urbana del espacio público, parafraseando a Deutsche (2001), no nos despeja las incertidumbres sobre las preocupaciones y ansiedades de nuestros ordenes sociales presentes, sólo nos devela un repertorio de lecturas posibles, más o menos críticas, más o menos optimistas, más o menos transformadoras del orden social dominante.

En este sentido la lectura del espacio público como un espacio de control y disputa, nos parece un marco sugerente para analizar y comprender los fenómenos recientes de perturbación del orden social dominante, que han tenido lugar en distintos lugares del mundo, a través de la manifestaciones de las denominadas multitudes inteligentes (Rheingold, 2002). Movimientos que utilizando soportes de comunicaciones electrónicos, han vuelto a hacer coincidir en un nuevo sentido, la dimensión comunicativa con el correlato urbano del espacio público.

\section{Bibliografía}

Arendt, H. (1958), The human condition. Chicago, IL: Universtity of Chicago Press. Trad. Cast.: La condición humana, Círculo de Lectores, 1999, Barcelona.

Atkinson, R., \& Flint, J. (2004), "Fortress UK? Gated Communities, the Spatial Revolt of the Elites and TimeSpace Trajectories of Segregation". Housing Studies, 19(6), 875-892. Retrieved from http://eprints.gla.ac.uk/37631/

Benevolo, L. (1993), La ciudad europea. Crítica. Barcelona.

Boddy, T. (1992), "Underground and overhead: building the analogous city". In M. Sorkin (Ed.), Variations on a theme park. The new American city and the end of public space (pp. 123-153). Hill and Wang: New York.

Boladeras, M. (2001), "La opinión pública en Habermas”. Análisi:Quaderns de Comunicació i Cultura, (26), 51-

70. Retrieved from http://dialnet.unirioja.es/servlet/oaiart?codigo=72418 database 
Borja, J. (2003), La ciudad conquistada. Alianza. Madrid.

Borja, J., \& Muxí, Z. (2001), Espacio público: Ciudad y ciudadanía. Editorial Electa. Barcelona.

Brill, M. (1989),"'Transformation, nostalgia, and illusion in public life and public place”. In I. Altman \& E. Zube. (Eds.) Public Places and Spaces. Vol. 10, Human Behavior and Environment. Plenum. New York.

Burte, H. (2003), "The space of challenge: Reflections upon the relationship between public space and social conflict in contemporary Mumbai". En (In)Visible Cities. Spaces of Hope, Spaces of Citizenship, Centre of Contemporary Culture of Barcelona.

Busquets, J. (2004), Barcelona la construcción urbanística de una ciudad compacta. Ediciones del Serbal. Barcelona.

Caldeira, T. (2000), City of walls: Crime, segregation and citizenship in sao paulo. University of California Press. Berkeley.

Carr, S., Francis, M., Rivlin, L., \& Stone, A. (1992), Public space. Cambridge University Press. Cambridge England.

Certeau, M. (2006), La invención de lo cotidiano 1 maneras de hacer. Universidad Iberoamericana. México D. F.

Certeau, M., Giard, L., \& Mayol, P. (2006), La invención de lo cotidiano 2 habitar, cocinar. Universidad Iberoamericana. México D. F.

Cisneros, J. (2003), “La privatización del espacio público". [Electronic version]. Revista Latina de Comunicación Social, año 6(56). Retrieved 13 de julio de 2007, from http://www.latindex.org/larga.php?opcion=1\&folio=13309\%20 database.

Consejo Europeo de Urbanistas, (2003), "Nueva carta de Atenas 2003". Extraído el 10 enero de 2012 de http://www.femp.es/files/566-3-archivo/CARTA\%20de\%20ATENAS\%20version\%20final.pdf.

Crawford, M. (1992), "The World in a shopping mall". In M. Sorkin (Ed.), Variations on a theme park. The new American city and the end of public space (pp. 3-30). Hill and Wang: New York.

Davis, M. (2003), Ciudad de cuarzo: Arqueología del futuro de los ángeles. Lengua de Trapo. Madrid.

Delfante, C. (2006), Gran historia de la ciudad. Abada. Madrid.

Delgado, M. (2001), Memoria y lugar el espacio público como crisis de significado tránsitos espacio público, masas corpóreas. Ediciones Generales de la Construcción. Valencia.

Deutsche, R. (2001). Agarofobia. In P. Blanco, J. Carrillo, J. Claramonte \& M. Expósito (Eds.), Modos de hacer. Arte crítico, esfera pública y acción directa (Universidad de Salamanca ed., pp. 289-356). Salamanca.

Di Masso, A (2009), Public space in conflict: place meaning as contested interaction and ideological action. Tesis doctoral no publicada.

Dixon, J., Levine, M., \& McAuley, R. (2006), "Locating impropriety: Street drinking, moral order, and the ideological dilemma of public space”. Political Psychology, 27(2), 187-206.

Engels, F. (1845), La situación de la clase obrera en inglaterra. Leipzig

Fernández Christlieb, P. (2004), El espíritu de la calle: Psicología política de la cultura cotidiana. Anthropos. Barcelona.

Ferry, J. (1995), "Las transformaciones de la publicidad". En Ferry, J., Wolton, D. Et al El nuevo espacio público, Gedisa, Barcelona.

Ferry, J., Wolton, D. Et al (1995), El nuevo espacio público. Gedisa, Barcelona. 
Foucault, M. (2005), Vigilar y Castigar. Ed. Siglo XXI. Madrid.

Goitia, Ch. (1970), Breve historia del urbanismo. Alianza editorial. Madrid.

Gorelik, A. (2008), “El romance del espacio público”. Alteridades, 18(36), 8-15.

Habermas, J. (1994), Historia y crítica de la opinión pública. Gustavo Gili. México D. F.

Hassenpflug, D. (2002). "Die europäische Stadt als Erinnerung, Leitbild und Fiktion”. Hassenpflug, D. (ed.), Die Europäische Stadt-Mythos und Wirklichkeit. LIT Verlag. Münster-Hamburg-London.

Joseph, I. (1999), Retomar la ciudad: El espacio público como lugar de la acción. Postgrado de Estética. Universidad Nacional de Colombia, sede Medellin. Medellín.

Lefebvre, H. (1973), El derecho a la ciudad. Península. Barcelona.

Mitchell, D. (1995), “The end of public space? People's Park, definitions of the public, and democracy". Annals of the Association of American Geographers, 85, 108-133.

Monclus, F. (2003), "The Barcelona Model: an original formula? From "Reconstruction" to Strategic Urban Projects (1979-2004)”, Planning Perspectives, vol.18, n.4, pp.399-421.

Mumford, L. (1979). La ciudad en la historia: Sus orígeneslano ed.). Ediciones Infinito. Buenos Aires.

Rabotnikof, N. (1997). El espacio público: Caracterizaciones teóricas y expectativas políticas. En Quesada, F.(ed). Filosofía Política I. Ideas politícas y movimientos sociales, pp.135-151. Trota-C.S.I.C. Madrid.

Radbruch, G.(1951), Introducción a la filosofia del derecho. Ed. Fondo de cultura económica Mexico.

Rheingold, H. (2002), Multitudes Inteligentes. La próxima revolución social. Gedisa. Barcelona.

Rossi, A. (1992), La arquitectura de la ciudad. Gustavo Gili. Barcelona.

Salcedo, R. (2002), "El espacio público en el debate actual: Una reflexión crítica sobre el urbanismo postmoderno". EURE (Santiago), 28(84), 5-19.

Secchi, B. (2005), “Ciudad moderna, ciudad contemporánea y sus futuros”. En M. R. Angel (Ed.), Lo urbano en 20 autores contemporáneos (UPC ed., pp. 145-158). UPC. Barcelona.

Sennett, R. (1974), El declive del hombre público. Península. Barcelona.

Sorkin, M. (1992), Variations on a theme park. The new American city and the end of public space. Hill and Wang: New York.

Thompson, J. (1996), “La teoría de la esfera pública”. Voces y Culturas Revista De Comunicacion, (10), 81-96.

Weintraub, J. (1995), "Varieties and vicissitudes of public space". En Kasinitz, Philip (ed). Metropolis: Center and symbol of our times, pp. 280-319. University Press. New York.

Wolton D. (1995), "La comunicación política: construcción de un modelo". En Ferry, J. et al. El nuevo espacio público, ed. Gedisa, pp 28-46. Barcelona.

Recibido: 15.02.2012

Aceptado: 11.03.2012 